GRADIATION\&APPLICATIONS

ISSN 2466-4294 (online) | rad-journal.org

Vol. 3 | Issue 1 | pp. 41-46, 2018

doi: 10.21175/RadJ.2018.01.008

Original research paper

\title{
NON-DESTRUCTIVE METHODS OF ${ }^{90}$ Sr MEASUREMENT ${ }^{*}$
}

\author{
D.M. Bondarkov, N.V. Kulich ${ }^{* *}$, D.E. Myznikov \\ M.V. Zheltonozhskaya, V.A. Zheltonozhsky
}

Institute for Nuclear Research of NAS of Ukraine, Kiev, Ukraine

\begin{abstract}
A new technique for ${ }^{90} \mathrm{Sr}$ activity measurement in fuel-containing materials with no radiochemical methods was developed. ${ }^{\circ} \mathrm{Sr}$ content was measured in fuel fragments of various types. Probability of $K_{x}$-radiation formation during the radioactive decay with the emission of ${ }^{\circ \circ} \mathrm{Sr}$ and ${ }^{\circ \circ} \mathrm{Y}$ electrons was measured. A comparison to radiochemical research data was made. A non-radiochemical technique of simultaneous measurements of ${ }^{90} \mathrm{Sr}$ and ${ }_{137 C s}$ activity in environmental samples based on spectrometric measurement of the electrons accompanying the isotope decay was proposed for measurements in situ (directly in places of radioactive contamination) and in vitro (in small living objects). Taking into account the contribution of ${ }^{40} \mathrm{~K}$ electrons to the total activity of test samples, up to $15^{-20 \%}$ improvement of the measurement accuracy for living beings is allowed, with ratio $A\left({ }^{137} \mathrm{Cs}\right) / \mathrm{A}\left({ }^{90} \mathrm{Sr}\right)$ being between 2 and 10o. Also, the improvement of up to 10-15\% for soil samples with changing the sample's activity by four orders of magnitude is observed. The results of spectrometric measurements were confirmed by traditional radiochemical research. The proposed methods allow us to execute prompt mass measurements of environment objects and small living objects directly in the places of radiation accidents. This is very important for the tasks of radioecological monitoring.
\end{abstract}

Key words: Strontium-9o, Cesium-137, Potassium-40, spectroscopy, autoionization, electrons, fuel containing materials, soils, living beings

\section{INTRODUCTION}

Radioactive ${ }^{90} \mathrm{Sr}$ decays by pure $\beta$-transition to ${ }^{\circ} \mathrm{Y}$ ground state, which also decays by pure $\beta$-transition to stable ${ }^{90} \mathrm{Zr}$. Limiting energy (Elim) of these $\beta$-transitions is 0.55 and $2.3 \mathrm{MeV}$, correspondingly.

Accordingly, basic measurement techniques for ${ }^{\circ} \mathrm{Sr}$ activity include radiochemical techniques for ${ }^{90} \mathrm{Sr}$ or ${ }^{90} \mathrm{Y}$ separation with further measurement of electrons by means of radiometers. Error of such measurements cannot be under $30 \%$, since all radiometers integrate the entire spectrum of electrons with respect to energy; and registration efficiency has non-linear energy dependence. In addition, the spectrum of electrons has a continuous energy distribution during a radioactive decay, similar to the Maxwell one, from zero to Elim. This particularly results in a poor accuracy of radiometry measurement techniques. And naturally, radiochemical procedures result in loss of test samples.

The techniques based on measurement of ${ }^{90} \mathrm{Sr}-{ }^{\circ}{ }^{\circ} \mathrm{Y}$ electron spectrum without radiochemical separation have recently been developed [1]. However, due to the complicated registration of electrons passing through a substance, the measurement accuracy of these techniques is $20-30 \%$. In addition, isotopes of ${ }^{137} \mathrm{Cs}$ and
${ }^{90} \mathrm{Sr}$, which make the greatest contribution to the formation of radiation burdens in the environment among all radionuclides that are released as a result of radiation accidents and nuclear tests are present in the environment in commensurable amounts. To address these problems, we have developed a technique that is based on co-current measurement of spectrum of the electrons that accompany the decay of ${ }^{90} \mathrm{Sr},{ }^{40} \mathrm{~K}$ and ${ }^{137} \mathrm{Cs}$.

While studying ${ }^{90} \mathrm{Sr}$ in fuel-containing materials (FCM), the main difficulties are caused by the fact that the processes of destruction, diffusion, etc. in FCM occur during decades. Therefore, when studying the behaviour of ${ }^{\circ} \mathrm{Sr}$ in $\mathrm{FCM}$, measurements should be taken during several years, in case the error of a single measurement exceeds 30\%. Naturally, studying the effects of either seasonal changes or emergencies in ${ }^{90} \mathrm{Sr}$ behaviour in temporary storage facilities for spent nuclear fuel or radioactive waste is out of the question. These data may be of great importance regarding the serious unsolved problems in radioactive waste processing and storage processes.

For the research, it is recommended to use such rare phenomenon as autoionization of atoms during $\beta$ decay [2]. This process occurs due to the fact that nuclear charge varies discontinuously during $\beta$-decay

\footnotetext{
* The paper was presented at the Fifth International Conference on Radiation and Applications in Various Fields of Research (RAD 2017), Budva, Montenegro, 2017.

kulich@kinr.kiev.ua
} 
D.M. Bondarkov et al., Non-destructive methods of ${ }^{90} \mathrm{Sr}$ measurement, Rad. Applic., 2018, 3, 1, 41-46

and, thus, the Coulomb field changes in exactly the same way. Consequently, the result is a "shake off" of electrons from different atomic shells, including Kshell. At the same time, a "hole" is being formed on Kshell and its filling results in the appearance of characteristic $\mathrm{K}_{\mathrm{x}}$-radiation. Measurement of $\mathrm{K}_{\mathrm{x}}$ radiation may allow determination of ${ }^{\circ} \mathrm{Sr}-{ }^{\circ} \mathrm{Y}$ activity. As such, this process has a probability of $10^{-3-10^{-4}}$ per a decay act, i.e. it can be used while studying the samples with high specific activity of ${ }^{\circ} \mathrm{Sr}$. Therefore, the probability of characteristic radiation formation during the decay of ${ }^{90} \mathrm{Sr}$ and the FCM characteristic spectra were studied in this paper for the development of a new measurement technique for ${ }^{\circ} \mathrm{Sr}$ activity.

\section{RESEARCH METHOdS AND Results}

Beta-spectrometric technique for ${ }^{90} \mathrm{Sr}$ and ${ }^{137} \mathrm{Cs}$ measurements for prompt and mass measurements in situ (in contaminated places) and in vitro (in small living objects)

The proposed technique is based on the measurement of electron energy distribution that

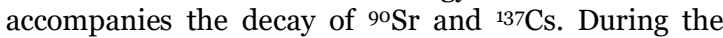
decay of ${ }^{90} \mathrm{Sr}$, two groups of electrons are emitted with limiting energy of 0.55 and $2.3 \mathrm{MeV}$ Moreover, during ${ }^{137} \mathrm{Cs}$ decay, electrons are emitted with limiting energy of $0.5 \mathrm{MeV}$ and $1.17 \mathrm{MeV}$, while conversion electrons from $\gamma 661 \mathrm{keV}\left(E_{e} \sim 0.63 \mathrm{MeV}\right)$ are also emitted.

Theoretically, the thicker an electron detection layer in $\beta$-detector is, the higher its efficiency is (and also ${ }^{\circ} \mathrm{Sr}$ assessment efficiency). However, presence of the activity, which is an order of magnitude higher than the one of ${ }^{137} \mathrm{Cs}$, and of increased external radiation background in a sample increase probability of the detection of $\gamma$-quantum ( $\gamma \quad 661 \mathrm{keV})$, the Compton $\gamma$-quantum and especially $\mathrm{x}$-ray emission $\mathrm{K}_{\mathrm{x}}$ $\mathrm{Ba}$ radiation, thus complicating the analysis of $\beta$ spectrum. In addition, a significant contribution to total $\beta$-spectrum can be made by ${ }^{40} \mathrm{~K}$ electrons $\left(E_{\mathrm{bn}}=\right.$ 1.3 MeV). In such conditions, a thinner detector should be used, whose detection layer thickness would be equal to the travel of $\beta$-electrons of ${ }^{\circ} \mathrm{Y}$ in phantom.

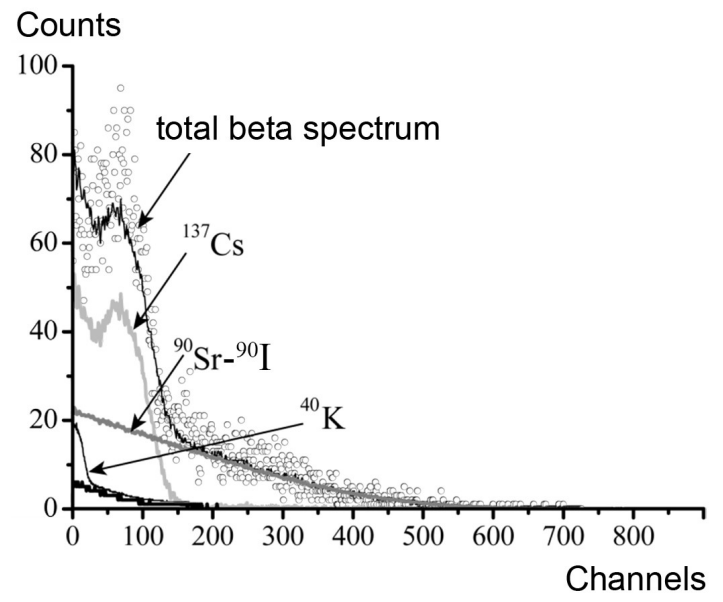

Figure 1. Fragment of experimental $\beta$-spectrum
We conducted the research using a plastic scintillation detector, $1 \mathrm{~mm}$ thick and $76 \mathrm{~mm}$ in diameter. To perform the efficiency calibration of experimental $\beta$-spectra, we prepared standard sources of ${ }^{40} \mathrm{~K},{ }^{90} \mathrm{Sr}$ and ${ }^{137} \mathrm{Cs}$, volumetric characteristics of which were close to the characteristics of experimental samples.

The experimental spectra were processed by the method of their comparison to the calibration range (Fig. 1), i.e. in this particular case, to the spectra obtained on the same spectrometer while using the standard sources of ${ }^{40} \mathrm{~K},{ }^{90} \mathrm{Sr}$ and ${ }^{137} \mathrm{Cs}+{ }^{\circ} \mathrm{Y}$ (phantoms).

The spectra of calibration sources and background were described by cubic splines and were further used to describe the experimental spectra. This process was implemented as follows.

Generally, for the approximation of experimental data $\left\{y_{i}\right\}, 1 \leq i \leq i_{0}$ by function $f(i, X)$, where $X$ is vector of fitted parameters $\left\{X_{j}\right\}, 1 \leq j \leq j_{\mathrm{o}}\left(j_{\mathrm{o}}\right.$ is number of fitted parameters), functional $(S(X))$ shall be minimized through the least square method:

$$
S(X)=\sum_{i=1}^{i_{0}} w_{i}\left[f(i, X)-y_{i}\right]^{2}
$$

where $w_{i}$ are weight factors that are usually chosen to be equal to the reciprocal square of experimental accuracy.

Main problems during ${ }^{90} \mathrm{Sr}$ measurements are caused by the fact that electrons have continuous spectrum, and their travel in a sample directly depends on its density.

To determine the functional minimum, derivatives $\partial \mathrm{S} / \partial \mathrm{X}_{\mathbf{j}}$ shall be set to zero, and the resulting system of equations shall be solved with respect to required parameters $X_{j}$.

The minimal value of functional $S(X)=S_{\text {o }}$ corresponds to the resulting solution of $X_{0}$. To determine the errors of parameters for each of them, equation $S\left(X_{\mathrm{o} j}+\delta X_{j}, X_{j}\right)=S_{o}+1$ shall be successively solved in reference to $\delta X_{j}$, i.e. it shall be determined with which deviation of the $j$-th parameter from an optimal value (at other fixed parameters) the value of functional $S$ is increased by 1 compared to the minimal one. And the parameter's error shall be equal to:

$$
\Delta X_{j}=\delta X_{j} \cdot R
$$

where $R$ is parameter that takes account of the fitting quality, the so-called " $\chi^{2}$ per freedom degree". below.

The technique for $\beta$-spectra processing is presented

First of all, the background spectrum (taking account of lifetime) shall be deducted from the processed spectrum and the spectra of calibration sources, each of which consists of $i_{0}$ channels with counting rate $N_{i}$ in $i$-th channel $1 \leq i \leq i_{0}$, that were measured in the course of lifetime $t_{j}$, index $j$ corresponds to the following: $\mathrm{o}$ is processed spectrum, 1 is calibration spectrum of $137 \mathrm{Cs}, 2$ is calibration spectrum of ${ }^{\circ} \mathrm{Sr}, 3$ stands for ${ }^{40} \mathrm{~K}$ :

$$
y_{j, i}=N_{j, i}-t_{j} / \text { tbackground } N_{\text {background }, I}
$$


D.M. Bondarkov et al., Non-destructive methods of ${ }^{90} \mathrm{Sr}$ measurement, Rad. Applic., 2018, 3, 1, 41-46

where $1 \leq i \leq i_{0}, 0 \leq j \leq 3$.

As a result of the subtraction, "pure" calibration spectra of ${ }^{40} \mathrm{~K},{ }^{137} \mathrm{Cs},{ }^{\circ} \mathrm{Sr}$ and the test sample spectrum are obtained. The latter includes unknown activities of

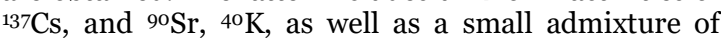
other activities, for example $\gamma$-nuclides of thorium and uranium series.

To compensate for this admixture, the quadratic background $a$ shall be added:

$$
a=\sum_{k=0}^{2} a_{k} i^{k}
$$

Another correction shall be made due to the fact that different densities of substance in test sample and in phantom may cause changes in calibration with respect to energy in the spectra of samples and in calibration spectra. To take account for this effect, the calibration spectra shall be modified as follows: The $\hat{\imath}^{-}$ th channel of calibration spectra shall be put in correspondence with the $i$-th channel of the processed spectrum, $\hat{\imath}=(1+c) i$. Obviously, $\hat{\imath}$ is not generally an integer. Therefore, the counting rate of calibration spectrum in the $\hat{\imath}$-th channel shall be determined by the linear interpolation method:

$$
y_{\hat{\imath}} \approx y \hat{\imath} o+\left(y_{\hat{\imath} o+1}-y \hat{\imath} o\right) \cdot\left(\hat{\imath}-\hat{\imath}_{o}\right),
$$

where $\hat{\imath}_{0}$ is an integer part of $\hat{\imath}$.

When channels from $i_{1}$ to $i_{2}$ are defined in a processed spectrum, the functional shall take the form:

$$
S(a, b, c)=\sum_{i=i_{1}}^{i_{2}} w_{i}\left[\sum_{j=1}^{2} b_{j}\left(y_{j . i}+\left(y_{j, i+1}-y_{j, i}\right) c \cdot i\right)+\sum_{k=0}^{2} a_{k} i^{k}-y_{i}\right]^{2}
$$

As a result of its minimization, needed parameters $b_{j}$ shall be determined. To obtain absolute activity A, they shall be multiplied by the activity of calibration sources and the lifetime ratio shall be taken into account:

$$
A_{j}=b_{j} \cdot \beta_{j} \cdot t_{o} / t_{j}
$$

where $\beta_{j}$ is activity of a corresponding phantom.
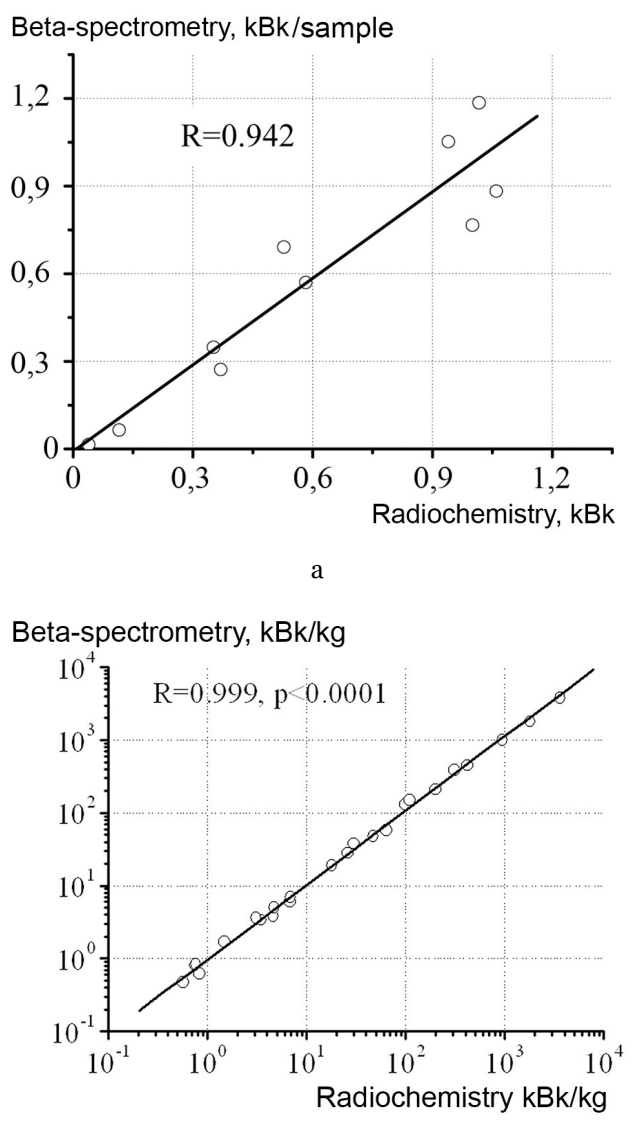

b

Figure 2. Comparison of the results of ${ }^{90} \mathrm{Sr}$ activity tests in living subjects (mice) (a) and in soil (b)
Fig. 2a shows the comparative analysis performed for small rodents with a body mass varying between 14

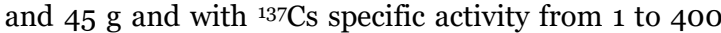
$\mathrm{Bq} / \mathrm{g}$ by spectroscopic and radiochemical methods. It was established that the results of $\beta$-spectrometry were consistent with the radiochemical analysis of data within $15-20 \%$, and ratio $A\left({ }^{137} \mathrm{Cs}\right) / A\left({ }^{\circ} \mathrm{Sr}\right)$ ranged between 2 and 100 .

The same comparison of ${ }^{\circ} \mathrm{Sr}$ measurement results in soil samples demonstrated a complete accordance within 10-15\%, with a four-order change in the samples' activity (refer to Fig. 2b). Please note that the improvement of errors compared to previous research was mainly due to the account of $4^{\circ} \mathrm{K}$ activities. With no account of this isotope's activity, the discrepancy ran up to $30 \%$ on average; and up to $100 \%$ for soil samples, when activities of ${ }^{90} \mathrm{Sr}$ and ${ }^{40} \mathrm{~K}$ were comparable [3]

Consequently, the developed technique takes account of physical and chemical state of test objects and instable operation of electronic systems in the field. This ensures an increased accuracy of measurements and reliability in operation of spectrometers.

This technique allows the study of ${ }^{90} \mathrm{Sr}$ and ${ }^{137} \mathrm{Cs}$ concentration in various environmental objects at

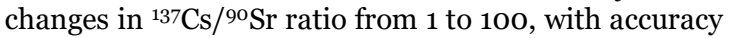
of above $20 \%$. Please note a higher sensitivity of this technique compared to measurements through ${ }^{\circ} \mathrm{Y}$ electrons $\left(E_{b n}=2.3 \mathrm{MeV}\right)$, when no more than 25-30\% of ${ }^{\circ} \mathrm{Y}$ electrons are actually used due to presence of ${ }^{\circ} \mathrm{K}$ electrons with the limiting energy of $1.3 \mathrm{MeV}$.

The technique for ${ }^{\circ} \mathrm{Sr}$ identification in fuelcontaining materials

To develop a technique for the identification of ${ }^{90} \mathrm{Sr}$ based on $\mathrm{K}_{\mathrm{x}}$-radiation, $\mathrm{K}_{\mathrm{x}}$-radiation yield from a standard calibration sample of ${ }^{90} \mathrm{Sr}-{ }^{\circ} \mathrm{Y}$ was measured by a semiconductor $1 \mathrm{~cm}^{3} \mathrm{Ge}$-detector with a thin beryllium input window. On measured $\gamma$-spectrum (Fig. 3), $\mathrm{K}_{\alpha^{-}}$and $\mathrm{K}_{\beta}$-radiation of ${ }^{\circ} \mathrm{Y}$ and ${ }^{90} \mathrm{Zr}$ sample were stably observed with the energy of 15.0, 15.8, 16.8 and $17.7 \mathrm{keV}$, respectively. 
D.M. Bondarkov et al., Non-destructive methods of ${ }^{90} \mathrm{Sr}$ measurement, Rad. Applic., 2018, 3, 1, 41-46

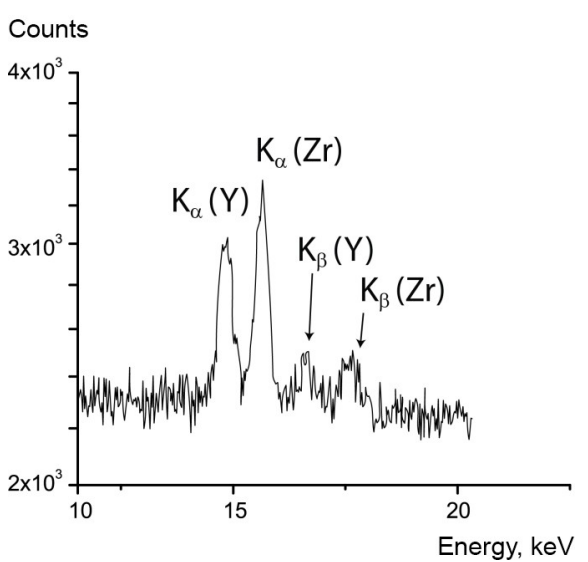

Figure 3. Gamma-spectrum of standard calibration sample of ${ }^{90} \mathrm{Sr}-{ }^{90} \mathrm{Y}$, which was measured on a semiconductor Ge-detector

Reference source of ${ }^{241} \mathrm{Am}$, which has $\mathrm{L}_{\alpha^{-}}$and $\mathrm{L}_{\beta}$ radiation with 13.9 and $17.7 \mathrm{keV}$ energy, was used for absolute calibration. As a result, it was determined that probability of autoionization of K-shell of ${ }^{90} \mathrm{Sr}$ and ${ }^{90} \mathrm{Y}$ per decay was equal to:

$$
\begin{aligned}
& P_{K}\left(9^{\circ} \mathrm{Y}\right)=3.21(16) \cdot 10^{-4}, P_{K}\left(9^{\circ} \mathrm{Zr}\right)= \\
& =4.19(21) \cdot 10^{-4}
\end{aligned}
$$

The same spectrometer was used to measure the samples of fuel particles of different origin:

- $\quad$ particle from ChNPP Unit 4 containing a great amount of uranium;

- particle from ChNPP Unit 4, which we identified to be a chernobylite fragment;

- fragment of undamaged fuel element.

Fig. 4 shows fragments of these samples' spectra in the energy ranges of $10-35 \mathrm{keV}$. This area includes gamma transitions of characteristic radiation of the basic radionuclides included into a test sample. Studying gamma transitions in this very energy range is crucial for the reduction of consistent errors during our research (see below).

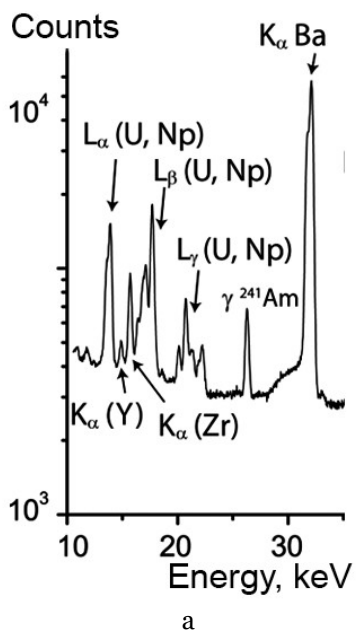

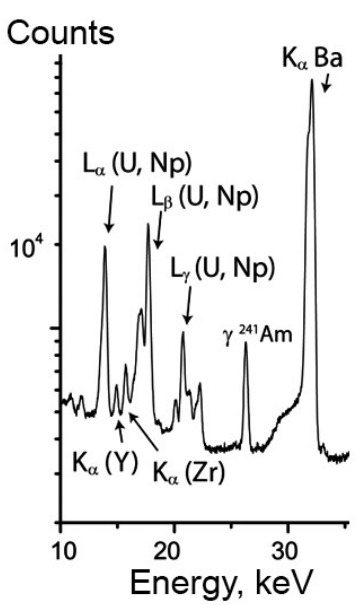

$\mathrm{b}$

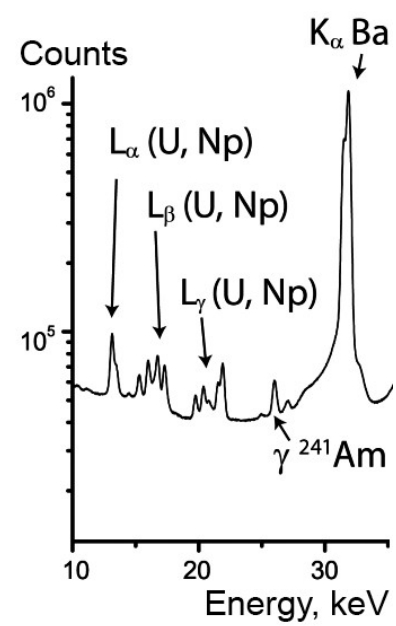

c

Figure 4. Fragments of gamma spectra measured by a semiconductor Ge-detector: chernobylite sampled from the inside of ChNPP Unit 4 (a), undamaged fuel element $(b)$, uranium particle fragment (c)

Table 1. Content of ${ }^{\circ} \mathrm{Sr}$ for different particles

\begin{tabular}{|c|c|c|c|}
\hline \multirow{2}{*}{ Isotope } & \multicolumn{3}{|c|}{ Activity, Bq×103 } \\
\cline { 2 - 4 } & $\begin{array}{c}\text { Fragment } \\
\text { of fuel element }\end{array}$ & $\begin{array}{c}\text { Fragment } \\
\text { of chernobylite }\end{array}$ & $\begin{array}{c}\text { Fragment } \\
\text { of uranium particle }\end{array}$ \\
\hline${ }^{90} \mathrm{Sr}$ & 50.7 & 15.8 & 42 \\
\hline${ }^{137} \mathrm{Cs}$ & 16.5 & 5.0 & 173 \\
\hline${ }^{241} \mathrm{Am}$ & 1.48 & 0.48 & 1.29 \\
\hline
\end{tabular}

The error for measuring of ${ }^{137} \mathrm{Cs}$ sium and ${ }^{241} \mathrm{Am}$ was $(4-5) \%$ for ${ }^{90} \mathrm{Sr}(6-10) \%$

As can be seen from the obtained spectra, $\mathrm{K}_{\mathrm{a}-}$ radiation of ${ }^{\circ} \mathrm{Y}$ is reliably distinguished in all samples, and its intensity is several percents of the intensity of ${ }^{241} \mathrm{Am} \mathrm{L} \mathrm{L}$-group. The peak/background ratio is also quite beneficial, and it allows an easy registration of ${ }^{\circ} \mathrm{Y}$ $\mathrm{K}_{\mathrm{a}}$-radiation against the Compton background of $\mathrm{K}_{\mathrm{x}^{-}}$ radiation of barium accompanying the decay of ${ }^{137 \mathrm{Cs}}$ via the conversion transition of gamma-transition with the energy of $661 \mathrm{keV}$. A more difficult situation is with ${ }^{90} \mathrm{Zr} \mathrm{K} \mathrm{K}_{\alpha}$-radiation. Zirconium is one of the basic structural materials inside ChNPP Unit 4, and therefore after it is being found in the structure of many fuel-containing materials from the accident. In the particles having a significant admixture of zirconium, the "holes" in Zr K-shell are formed due to the electron ionization processes due to radioactive

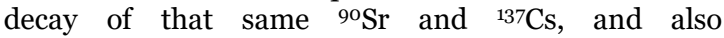
photoionization due to the photoelectric effect of gamma transitions. And, as well as in the case of autoionization, the same $\mathrm{K}_{\mathrm{x}}$-radiation of $\mathrm{Zr}$ is formed during $\beta$-decay of ${ }^{\circ} \mathrm{Y}$. Division of peaks from these 
radiations is impossible; and therefore $\mathrm{K}_{\mathrm{x}}$-radiation of $\mathrm{Zr}$ can only be used as a confirmatory factor when studying fuel containing materials through this method. All principal measurements should be taken through $\mathrm{K}_{\mathrm{a}}$-radiation of ${ }^{\circ} \mathrm{Y}$.

Table 1 shows the results of ${ }^{90} \mathrm{Sr}$ content for different particles. The data on ${ }^{137} \mathrm{Cs}$ and ${ }^{241} \mathrm{Am}$ activity are presented there for comparison.

To verify the obtained results, radiochemical research of ${ }^{\circ} \mathrm{Sr}$ content in test samples of the particles was conducted with radiochemical oxalate method by daughter ${ }^{90} \mathrm{I}$. The ratio of $\mathrm{A}\left({ }^{\circ} \mathrm{Sr}\right)$ radiochem $/ \mathrm{A}\left({ }^{\circ} \mathrm{Sr}\right)$ was 0.95 for the fuel element fragment; for the chernobylite fragment it amounted to 1.1; and for the fragment of uranium particle it was 1.2.

Particularly, during radiochemical liberation of ${ }^{90} \mathrm{Sr}$ from the fragment of fuel element, its activity was $3.25 \cdot 10^{3} \mathrm{~Bq}$, and during our measurements of the same fragment of fuel element, it amounted to $3.07(9) \cdot 10^{3}$ $\mathrm{Bq}$. As discussed above, the error of radiochemical research is approximately 30\%. As it can be seen, a high level of coincidence of the obtained data is observed within these $30 \%$.

The statistical error of our measurements was not more than $2-3 \%$. The systematic error was registered by specific software.

The main source of errors in low energy range measurements is spectrometer calibration accuracy with respect to absolute efficiency of $\gamma$-rays registration. With respect to gamma-quantum $\varepsilon(E)$ registration efficiency, the detector was calibrated by formula [4]:

$$
\ln \varepsilon(E)=\sum_{j=0}^{m} a_{j}(\ln E)^{j}
$$

where energy $E$ is preset as $\mathrm{keV}$.

To calculate the calibration parameters, several isotopes may be used, even if their mass ratio in calibration sample is unknown. Standard sources, such as ${ }^{241} \mathrm{Am}$ and ${ }^{137} \mathrm{Cs}$, were used in order to link the obtained results to the radionuclides' yield. At the same time, the function is minimized:

$$
S(a, b)=\sum_{i=1}^{N} \sum_{k=1}^{n_{j}} w_{i k}\left(f\left(E_{i k}\right)-b_{i} \varphi_{i k}\right)^{2}
$$

where $N$ is number of isotopes, $n_{i}$ is number of lines of the $i$-th isotope, $b_{i}$ is weight factor of the $i$-th isotope, $E_{i k}$ is energy of the $k$-th line of the $i$-th isotope, $f$ is calibration function, $\varphi_{i k}$ is logarithm of measured and table intensities ratio for the $k$-th line of the $i$-th isotope, factors $w_{i k}$ are inversely proportional to the sum of squares of relative errors of a line's measured and table intensities. Weight factor of the first isotope $b_{1}$ is taken to be equal to one.

Differentiation with respect to $a, b$ and equation of derivative to $o$ results in a system of linear equations

$$
M\left(\begin{array}{l}
a \\
b
\end{array}\right)=Y
$$

whereof calibration parameters $a_{j}$ and relative activity of isotopes $b_{i}$ are determined. Knowing an isotope absolute activity, it is possible to obtain an absolute calibration curve.

Here, an important point should be mentioned. It is proposed to identify ${ }^{90} \mathrm{Sr}$ by comparing intensity $\mathrm{K}_{\mathrm{a}}$ of ${ }^{\circ} \mathrm{Y}$ and $\mathrm{L}_{\alpha}$ of ${ }^{241} \mathrm{Am}$, and absolute activity shall be determined by a comparison with ${ }^{241} \mathrm{Am}$ activity, which can be obtained based on $59 \mathrm{keV} \gamma$ yield. Therefore, we are interested in the registration efficiency ratio $\eta=\varepsilon_{k} / \varepsilon_{l}$ for two different energies that are similar in magnitude, $E_{k}$ and $E_{l}$. The accuracy of this ratio is significantly higher than the accuracy of efficient factors taken by them. When used for calibration with respect to function efficiency, relative error $\delta \eta$ shall be equal to the absolute error $\Delta(\ln \eta)$ :

$$
\Delta \ln \frac{\varepsilon_{k}}{\varepsilon_{i}}=\sqrt{S_{0} \sum_{i, j=0}^{m} M_{i j}^{-1}\left[\left(\ln E_{k}\right)^{i}-\left(\ln E_{l}\right)^{i}\right]}\left[\left(\ln E_{k}\right)^{j}-\left(\ln E_{l}\right)^{j}\right]
$$

where $S_{\mathrm{o}}$ is minimized value, $M_{i j^{-1}}$ are elements of the matrix, which is inverse of matrix $M$, that determine variances and covariances of calibration parameters $a$. It is easy to see that the closer to each other energies $E_{k}$ and $E_{l}$ are, the smaller the error of ratio $\eta$ is. This error is also significantly reduced because of the crosscorrelation of calibration parameters $a$. The fact that the measurement error for yield of $\mathrm{L}_{\alpha^{-}} \mathrm{L}_{\beta}$-groups of ${ }^{241} \mathrm{Am}$ is approximately $1 \%$ [5] and the efficiency curve in this area has a subdued form, allows interpolation of the efficiency factors for our transitions within the accuracy of $\leq 0.5 \%$. Actually, we can exclude contribution of the approximation errors and use statistical accuracies.

Consequently, having measured the absolute activity of ${ }^{241} \mathrm{Am}$ in $\gamma$-line of $59 \mathrm{keV}$ (in such a case, an error is being significantly minimized due to the heterogeneity of samples and their different densities), ${ }^{90} \mathrm{Sr}$ activity shall be determined by the formula:

$$
A\left({ }^{\circ 0} \mathrm{Sr}\right)=404 A\left({ }^{241} \mathrm{Am}\right) \frac{I\left(K_{\alpha} Y\right)}{I\left(L_{\alpha} A m\right)} .
$$

For these measurements, a measurement error of $4-5 \%$ is achieved quite easily. We believe this opens up new opportunities for studying the behavior of ${ }^{\circ} \mathrm{Sr}$ in radioactive waste on its storage sites.

While conducting the studies with non-dominant ${ }^{241} \mathrm{Am}$ activity, the measurements are carried out by comparing the yields of $\mathrm{L}_{\alpha}$-groups of ${ }^{\circ} \mathrm{Y}$ and ${ }^{\circ} \mathrm{Zr}$ with the release of $\mathrm{K}_{\mathrm{a}}$ of $\mathrm{Ba}$ by the formulas:

$$
\begin{aligned}
& A\left({ }^{90} \mathrm{Sr}\right)=190 A\left({ }^{137 \mathrm{Cs})} \frac{I\left(K_{\alpha} Y\right)}{I\left(K_{\alpha} B a\right)} .\right. \\
& A\left({ }^{\circ} \mathrm{Sr}\right)=146 A\left({ }^{137 \mathrm{Cs})} \frac{I\left(K_{\alpha} Z r\right)}{I\left(K_{\alpha} B a\right)} .\right.
\end{aligned}
$$

(14),

While using expression ( 5 ) for the energy of $15 \mathrm{keV}$ ( $\mathrm{L}_{\alpha}$-groups of ${ }^{\circ} \mathrm{Y}$ and ${ }^{90} \mathrm{Zr}$ ) and of $33 \mathrm{keV}\left(\mathrm{L}_{\alpha}\right.$ of $\mathrm{Ba}$ ), it can be seen that the errors in registration efficiency accuracies for these energies do not exceed $1.5 \%$. Therefore, they can actually be ignored; and for ${ }^{90} \mathrm{Sr}$ measurements by means of this method, the error shall 
D.M. Bondarkov et al., Non-destructive methods of ${ }^{90} \mathrm{Sr}$ measurement, Rad. Applic., 2018, 3, 1, 41-46

consist of the statistical error and errors in the autoionization probability data (5\%).

\section{REFERENCES}

1. M. D. Bondarkov, A. M. Maximenko, V. A. Zhetonozhsky, "Non radiochemical technique for ${ }^{90} \mathrm{Sr}$ measurement," Radioprotection, vol. 37, no. C1, pp. C1-927 - C1-931, Feb. 2002. DOI: $10.1051 /$ radiopro/2002226

2. V. A. Zheltonozhskyi, N. V. Strilchuk, "Study of the dependence of the excitation probability of an atom in the $\beta$-decay of the electron energy," The RAS Journal, vol. 66, no. 10, pp. 1450, 2002.

3. А. И. Липская, М. В. Желтоножцкая, Н. В. Кулич и др., „Поведение радионуклидов в лесных экосистемах, прилегающих к 30-километровой зоне чаэс,“ Наукові праці. Серія Техногенна безпека, т. 185, но. 173, стр. 59 - 65, 2012. (А. I. Lypska, M. V. Zheltonozhska, N. V. Kulich et al., "Behavior of radionuclides in the forest ecosystems adjacent to 30-km Chornobyl zone," Proceedings. Industrial safety series, vol. 185 , no. 173, pp. $59-65$, 2012.)

Retrieved from: http://tb.chdu.edu.ua/article/view/66 220/61582;

Retrieved on: Feb. 20, 2018

4. В. П. Хоменков, „Дослідження атомно-ядерних ефектів у процесі внутрішньої конверсії гаммапроменів," дисерт. канд. фізико-математичних наук, Національна Академія Наук України, Інститут ядерних досліджень, Київ, Україна, 2003. (V. P. Khomenkov, "Research of atomic and nuclear effects in the process of internal conversion of gamma rays," Cand. Sc. Dissertation, National Academy of Sciences of Ukraine, Institute for Nuclear Research, Kiev, Ukraine, 2003.)

5. E. Browne, R. B. Firestone, Table of Radioactive Isotopes, New York (NY), USA: John Wiley \& Sons. Inc., 1986.

DOI: 10.1002/bbpc.19870910459 